\title{
Personal therapeutic approach in Gestalt therapists working with clients suffering from medically unexplained psychosomatic symptoms
}

\author{
Jan Roubal, Roman Hytych, Michal Čevelíček, Tomáš Řiháček \\ Department of Psychology, Masaryk University, Brno, Czech Republic
}

\begin{abstract}
Treatment specificity and adherence to treatment manuals represent essential components of the medical model in psychotherapy. The model assumes that psychotherapists who work with the same type of clients and who identify with the same theoretical approach work very similarly. This study illustrates the shortcomings of that assumption and explores how therapists' individuality forms and shapes their unique approaches that resonate with their own personalities, inclinations, and worldviews. Semi-structured interviews with eight Gestalt therapists working with clients who experienced medically unexplained physical symptoms were analysed using the grounded theory method. Considerable differences were found among the therapists within four domains of the personal therapeutic approach, namely Case Conceptualization, Therapeutic Task, Therapist's Position, and Alternative Strategy. However,

Correspondence: Jan Roubal, Department of Psychology, Faculty of Social Studies, Masaryk University, Jostova 10, 60200 Brno, Czech Republic. Tel.: +420.731.052.063.

E-mail: jan.roubal.cz@gmail.com

Citation: Roubal, J., Hytych, R., Čevelíček, M., Řiháček, T. (2021). Personal therapeutic approach in Gestalt therapists working with clients suffering from medically unexplained psychosomatic symptoms. Research in Psychotherapy: Psychopathology, Process and Outcome, 24(3), 295-305. doi: 10.4081/ripppo.2021.535 regardless of the differences, all the therapists endeavoured, either implicitly or explicitly, to convey to the clients what they considered to be healthy functioning. There is considerable diversity in the way therapists work even when they subscribe to the same psychotherapeutic approach and work with the same type of clients. The exploration of psychotherapists' usual strategies, as well as the alternative strategies they use when their usual strategies do not work, appears helpful for capturing their personal therapeutic approaches.
\end{abstract}

Acknowledgements: the authors thank Jana Vránová and Jana Máchová for their help with data collection.

Funding: this study was supported by the Czech Science Foundation under Grant GA18-08512S.

Contributions: JR and RH contributed mainly with data analysis and with writing the Results and Discussion sections. MC and TR contributed mainly as analysis auditors and with writing the Introduction and Methods sections. All the authors reviewed the whole article.

Conflict of interest: the authors declare no potential conflict of interest.

Ethical approval and consent to participate: the project was approved by the Research Ethics Committee of the Masaryk University (ref. no. EKV-2016-006).

Availability of data and material: the data are available upon request from the first author.

See online Appendix for additional material.

Received for publication: 9 March 2021.

Revision received: 29 September 2021.

Accepted for publication: 20 October 2021.

This work is licensed under a Creative Commons Attribution NonCommercial 4.0 License (CC BY-NC 4.0).

${ }^{\circ}$ Copyright: the Author(s), 2021

Licensee PAGEPress, Italy

Research in Psychotherapy:

Psychopathology, Process and Outcome 2021; 24:295-305

doi:10.4081/ripppo.2021.535
Key words: Personal therapeutic approach; medically unexplained physical symptoms; Gestalt therapy; grounded theory method; therapeutic strategy.

\section{Introduction}

Psychotherapists tend to develop, either deliberately or unintentionally, individualized approaches that resonate with their personality, inclinations, and worldviews (Fernández-Alvarez, Gómez, \& García, 2015; Řiháček \& Roubal, 2017). These personal approaches are created from a blend of one's theoretical orientation, natural skills and abilities, personal history and experiences, accumulated professional experience, and their own experience in therapy (Maruniaková, Řiháček, \& Roubal, 2017; Maruniaková \& Řiháček, 2018). Indeed, it has been shown that the proportion of variance explained by differences among therapists is much higher than the proportion explained by differences among treatments (Baldwin \& Imel, 2013). Therapists' individual approaches seem inseparable from their personalities and cannot be fully standardized.

Such a point of view contrasts with the medical model in psychotherapy (Wampold \& Imel, 2015). Assessing psychotherapists' adherence to a treatment manual became an integral part of randomized clinical trial methodology (Waltz, Addis, Koerner, \& Jacobson, 1993). 
Technique is regarded as the active ingredient of treatment and, therefore, a group of psychotherapists applying the same therapeutic approach are expected to think and behave in a very homogeneous manner throughout the therapeutic process. Another assumption embedded in the medical model is treatment specificity (Wampold \& Imel, 2015). Various disorders are assumed to have different causes. Since treatments are expected to specifically address these causes, distinct techniques are prescribed for different disorders and conditions. This also naturally leads to the standardization of treatments and to a demand for psychotherapists to follow these specific guidelines.

In the present study, we challenge the above-described assumptions of the medical model using the concept of a

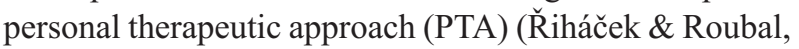
2017; Maruniaková, Řiháček, \& Roubal, 2017; Maruniaková \& Řiháček, 2018) as it naturally appears in daily psychotherapy practice. We start from the position of seeing psychotherapy as a primarily interpersonal process in which the technique cannot be separated from the relationship, and the therapist participates in the process with his or her whole personality (e.g., Orlinsky \& Rønnestad, 2005). We are equally critical of the assumption that psychotherapists, if properly trained, are, in fact, interchangeable (Elliott, 1998; Orlinsky \& Ronnestad, 2005).

We also question the concept of treatment specificity for different kinds of mental health problems. Categorical concepts of psychopathology are being revisited and adjusted in favour of more general psychopathology factors (Caspi et al., 2014; Hopwood et al., 2019) and the same therapeutic change mechanisms have been identified across various mental health issues (Wampold, 2015). From this point of view, we may expect that change mechanisms targeted by different therapists would be applicable across diagnostic categories, even if they work with a specific group of clients. Consequently, treatment strategies would differ across psychotherapists because they would be influenced by the therapists' personal preferences rather than the diagnostic category in question.

In the present study, we deliberately chose a setting where a rather uniform approach to treatment would be expected: the psychotherapists were all trained in the same psychotherapy approach (Gestalt therapy), and their clients all had the same kind of clinical symptomatology (medically unexplained somatic symptoms, MUPS). Under these conditions, we explored how therapists' individuality forms and shapes their own unique psychotherapy approaches.

The term MUPS is being used for a somatic symptom experience that lacks any medical explanation (Brown, 2007). These clients, after a series of unsuccessful medical consultations, are often referred to psychotherapy and are considered difficult to treat (Heijmans et al., 2011; Luca, 2011). This study is a part of a larger project that included the analysis of clinical strategies used in the treatment of MUPS by psychotherapists of various theoretical orien- tations. In a previous study, we analysed data from the whole sample (Čevelíček et al., 2019). For the purpose of this study, however, we selected only those for whom Gestalt therapy was their primary theoretical orientation. This approach was chosen simply because it was the most represented one in the sample.

Change mechanisms emphasized in humanistic and experiential psychotherapies for the treatment of MUPS include validating clients' experience of their somatic symptoms, increasing bodily and emotional awareness and regulation, helping clients understand how their symptoms are grounded in their relational and cognitive patterns, and nonjudgmentally accepting the presence of symptoms while focusing on client resources and abilities, rather than symptoms and deficits ( ̌̌iháček \& Čevelíček, 2019). Several change mechanisms used in Gestalt psychotherapy have received empirical support when examined across different psychotherapeutic approaches. These mechanisms include increasing symptom acceptance, which represents the willingness to experience unwanted emotions, thoughts, and bodily sensations with the ability to act despite symptoms; development of coping strategies that can build on clients' strengths; instilling positive expectations from the treatment; helping clients engage in pleasurable activities and reducing their fear of symptoms; helping them sense more control over symptoms; and fostering working alliance (Pourová et al., 2020).

In the present study, while keeping both the self-identified psychotherapeutic approach and the target client population constant, we aimed to explore the inter-individual differences in therapists' PTA. Clients with MUPS are considered difficult to treat and we can therefore expect that a significant portion of cases may be viewed as unsuccessful by the psychotherapists (Heijmans et al., 2011). Therefore, to explore diverse strategies within psychotherapists' PTAs, we asked them about both successful and unsuccessful cases. This was motivated by the intention to explore the alternative strategies they used when they perceived their usual strategy as unsuccessful. Through a qualitative analysis of interviews with therapists, we sought to answer two complementary research questions. The first one was focused on the uniqueness of each therapist's personal approach: In what ways do Gestalt therapists differ from each other when working with MUPS clients? The second one, on the other hand, aimed to identify common patterns behind the heterogeneity: What are the common principles that, on a meta-level, govern the functioning of the individualized therapist's personal approach?

\section{Materials and methods}

\section{Participants}

Eight self-identified Czech Gestalt psychotherapists, four males and four females, all Caucasian, aged from 38 
to $54(M=44.4, S D=6.0)$. Their psychotherapy experience ranged from 14 to 28 years $(M=17.9 ; S D=4.9)$, and their specific experience with clients suffering from MUPS ranged from 5 to 19 years $(M=11.8 ; S D=4.3)$. All of them had worked with clients suffering from MUPS for at least 5 years. With regard to their professional background and education, two were psychiatrists and six were psychologists. All the participants had finished graduate-level academic training in their respective professions and then finished a certified psychotherapy training with a minimum of 750 training hours. Most of them had completed additional shorter trainings, two were trained in body-psychotherapy, two in systemic and family therapy, one in hypnosis and CBT, one in relaxation and imagination techniques, one in EFT, and one in supervision.

Gestalt therapy is one of the humanistic psychotherapies and is based on a phenomenological exploration of the processes of experiencing as they emerge in the therapeutic meeting (Francesetti, Alcaro, \& Settanni, 2020). Gestalt therapy, as an existential and relational approach, focuses on what the client and the therapist experience and how they make meaning of the co-created therapeutic situation. Symptoms, including MUPS, are seen as products of the creative self and display human uniqueness (Perls, Hefferline, \& Goodman, 1951). Psychopathology represents an originally unique creative adjustment in a difficult situation (Roubal, Francesetti \& Gecele, 2017). However, once the situation is resolved, the adjustment no longer serves the client's needs and restricts their ability to have satisfying contact with their environment. In this sense, symptoms can be seen as a plea for a kind of contact that would render the symptoms themselves unnecessary (Sichera, 2001), which is explored in the hereand-now relationship with the therapist.

Gestalt therapy, in general, focuses on the mutual bodily processes of affective co-regulation between the client and the therapist (Francesetti, 2019; Jacobs \& Hycner, 2009; Philippson, 2009), and also focuses its approach on psychosomatic symptoms (Iaculo, 1997; Kepner, 1993; Nemirinskiy, 2013). It does not deal with the human body per se but with contact in the body/environment field (Perls, Hefferline, \& Goodman, 1951). Psychosomatic symptoms can be perceived as a retroflected form of contact with the world (Nemirinskiy, 2013) which is actualized in the therapy situation, allowing for the exploration of the relational aspects of psychosomatic symptoms. However, Gestalt therapy as a humanistic approach does not primarily focus on the treatment of psychosomatic symptoms. Rather, it aims to support the human growth of the clients in the unique contexts of their lives. Despite the internationally widespread network of practitioners, rich theoretical developments, as well as a growing amount of research literature (Barber, 2006; Brownell, 2008, 2016; Strümpfel \& Goldman, 2001; Roubal et al., 2016; Strümpfel, 2006), specific research on MUPS is vastly missing in the Gestalt therapeutic tradition, and
Gestalt therapy relies on studies of other humanistic and experiential approaches.

\section{Procedure}

Recruitment. As an invitation to participate in the research, an email with a short summary of the research goals and the interview description was sent to 71 Czech psychotherapists working with clients suffering from MUPS. We used the following inclusion criteria: i) completed psychotherapy training; ii) at least five years of experience working with clients suffering from MUPS; and iii) willing to talk with researchers about one successful and one unsuccessful case of psychotherapy with clients suffering from MUPS. Thirty-one of them were willing to participate and met the inclusion criteria and eight selfidentified as Gestalt therapists (more details in Cevelicek et al., 2019). The project was approved by the Research Ethics Committee of Masaryk University (ref. no. EKV2017-029-R1).

Data collection. From February to May 2018, two research assistants conducted the interviews. The duration of the interviews ranged from 1.5 to 2 hours. We used a semi-structured interview schedule with each therapist to explore one successful and one unsuccessful psychotherapy case of a client with MUPS. We excluded cases with other serious mental health problems or severe addiction. While no specific time limit was used to exclude cases, participants were instructed to select recent cases so that they could recall the treatment process in detail. The interview schedule covered three themes: i) descriptive information about the client (somatic symptoms; other somatic and mental health problems; age; sex; education; occupation; family situation; and treatment motivation); ii) the client's understanding of their problems and the psychotherapist's conceptualization of the client's problems; and iii) the psychotherapy process in detail (see $A p$ pendix for the interview schedule). All interviews were audio-recorded and transcribed for analysis.

There were several reasons for this strategy. First, by focusing on specific cases, we aimed to eschew the psychotherapists' theorizing about the treatment of MUPS in general and explore their genuine experience. Second, the choice of one successful and one unsuccessful case allowed for the exploration of strategies the psychotherapists used in different scenarios. Third, from an idiographic perspective, this approach should help explore psychotherapists' styles when working with specific clients and allow for detailed descriptions of those styles.

Data analysis. The data was analysed by the first two authors using grounded theory methodology (Glaser \& Strauss, 1967; Charmaz, 2006). The analysis proceeded in the following steps: i) Using open coding procedures, each interview was analysed by one of the first two authors as a separate case in order to investigate the personal approach of each therapist. The emerging concepts were then provisionally interconnected into a working theoretical model 
for each case separately. Each of the first two authors analysed a half of the interviews; ii) Each case-specific model was audited and further developed by the other of the first two authors (i.e., the one who did not analyze the particular case in Step 1). Then both authors discussed and consolidated each model via a teleconference. Afterwards, the case-specific models were validated by the last two authors; iii) Using the constant comparison method and theoretical coding procedures, the case-specific models were compared to each other, and, within this process, a paradigmatic model was developed to facilitate inter-case comparisons. The paradigmatic model consisted of four domains, namely Case conceptualization; Therapeutic task; Therapist's position; and Alternative strategy. Each case-specific model was then reformulated using this paradigmatic model to allow for more systematic comparisons among cases. The paradigmatic model was validated by the last two authors; iv) To capture the uniqueness of each case, we strived to develop a title for each that would express its essence in a more holistic manner; v) On a more abstract level, we searched for common patterns across the whole sample related to the functioning of the individualized therapist's personal approach; vi) Due to the space limitations of this article, we chose four cases that best represented the heterogeneity of the personal therapeutic approaches and present them in the Results section.

Trustworthiness of the results was reinforced by: i) Every case being analysed by two researchers, where one of them conducted the primary analysis and the other served as an auditor; and ii) Using the principle of consensuality (Hill, 2012) as a means of securing the validity of the analytic procedure - at each step of the analysis, findings were personally discussed until a consensus between all four authors was reached that the created concepts were grounded in the data, understandable, and relevant.

\section{Results}

As a means for the description of the participants' PTA, we developed four domains. These domains emerged from the data and included: i) Case conceptualization of how a therapist understands the client's difficulties; ii) Therapeutic task deduced from the conceptualization; iii) Position from which the therapist approaches their clients; and iv) Alternative strategy used when the main strategy does not work.

We use these domains to structure the vignettes of the therapists. Each vignette is first characterized by a title in the form of a statement paraphrasing the strategy typical for the particular psychotherapist. Due to space limitations, we selected four cases that best represent the heterogeneity of the sample. The therapists' names used in the Results section are fictional to preserve participant anonymity (see Table 1 for a more schematic depiction of the differences among the four therapists). Some contrasts that may not be apparent from the narrative vignettes are more readily visible in Table 1 . For example, while Magda and Veronika are characterized by a similar approach to Conceptualization (MUPS are associated with unexpressed emotions), they differ considerably in the Task and Position domains: Veronika uses theoretical models to teach the client and offer coping strategies, whilst Magda relies on corrective relational experience provided by an accepting non-expert therapist.

\section{Vincent: I lead the client to change her life}

Vincent (Therapist 4) is a 53-year-old male psychiatrist with 19 years of psychotherapy practice.

Case conceptualization. According to Vincent, symptoms signalize that the client is not living a healthy lifestyle. MUPS are caused by the client being over-

Table 1. Summary of working strategies characterizing personal therapeutic approach.

\begin{tabular}{|c|c|c|c|c|}
\hline & $\begin{array}{l}\text { Conceptualization } \\
\text { (How a therapist } \\
\text { understands the } \\
\text { client's difficulties) }\end{array}$ & $\begin{array}{l}\text { Therapeutic task } \\
\text { (What a therapist } \\
\text { sees as a useful } \\
\text { therapeutic strategy) }\end{array}$ & $\begin{array}{l}\text { Position } \\
\text { (What is the relational } \\
\text { position from which } \\
\text { a therapist approaches } \\
\text { the client) }\end{array}$ & $\begin{array}{l}\text { Alternative strategy } \\
\text { (How a therapist changes their } \\
\text { approach when perceiving their } \\
\text { work as unsuccessful) }\end{array}$ \\
\hline $\begin{array}{l}\text { Vincent } \\
\text { I lead the client to } \\
\text { change her life }\end{array}$ & $\begin{array}{l}\text { MUPS are caused by } \\
\text { existential anxiety }\end{array}$ & $\begin{array}{l}\text { Broadening awareness } \\
\text { to facilitate decisions } \\
\text { about life changes }\end{array}$ & $\begin{array}{l}\text { Doctor-like authority that } \\
\text { legitimizes the client's } \\
\text { experiences }\end{array}$ & $\begin{array}{l}\text { Education and medication for } \\
\text { symptomatic relief }\end{array}$ \\
\hline $\begin{array}{l}\text { Magda } \\
\text { I cradle the client } \\
\text { patiently }\end{array}$ & $\begin{array}{l}\text { MUPS are expression of } \\
\text { frozen emotional processes }\end{array}$ & $\begin{array}{l}\text { Building self-support and } \\
\text { compassionate approach } \\
\text { to oneself }\end{array}$ & $\begin{array}{l}\text { Patient, not-knowing, and } \\
\text { non-hierarchical support }\end{array}$ & Being even more patient \\
\hline $\begin{array}{l}\text { Irena } \\
\text { I let the client learn } \\
\text { from a strong woman }\end{array}$ & $\begin{array}{l}\text { Body speaks symbolically } \\
\text { through MUPS }\end{array}$ & $\begin{array}{l}\text { Redirect the client back } \\
\text { to feelings }\end{array}$ & $\begin{array}{l}\text { Authentically present } \\
\text { authority that insists on } \\
\text { what needs to be done }\end{array}$ & Providing opportunity to share \\
\hline $\begin{array}{l}\text { Veronika } \\
\text { I teach the client to use } \\
\text { emotions properly }\end{array}$ & $\begin{array}{l}\text { MUPS are caused by } \\
\text { restraining emotions }\end{array}$ & $\begin{array}{l}\text { Teach the client proper } \\
\text { emotional management }\end{array}$ & $\begin{array}{l}\text { Initiator of change requiring } \\
\text { client to assume } \\
\text { responsibility for that change }\end{array}$ & $\begin{array}{l}\text { Accepting the 'resistance' and } \\
\text { finishing therapy }\end{array}$ \\
\hline
\end{tabular}

MUPS, medically unexplained somatic symptoms. 
whelmed by the number of tasks imposed upon him, which is also related to his personal perfectionist nature and his inability to perceive the existential dimension of life. MUPS are caused specifically by existential anxiety, which the client is unaware of and which he manages in a dysfunctional way oriented only to 'material criteria':

In this case, the most primitive issues mattered: to be as rich as possible so the family has a good life. Nothing was really important; the meaning of life or the universe were not of any interest to him. So maybe this is why he had pain in his back and belly (...) He experienced great stress and, in fact, existential anxiety which he was not aware of... (...) For such a person, financial safety is never enough, he repeatedly succumbs to anxiety, because the reason for it lies somewhere else.

Being goal-oriented cannot provide an answer to existential anxiety, the cause of MUPS. Therefore, it is important to understand the client's existential values and to direct him towards a lifestyle that allows for their fulfilment.

Therapeutic task. The task of psychotherapy is to understand what change in lifestyle is being indicated by the somatic symptoms. Vincent offers a psychological perspective on MUPS and assesses whether the client can 'accept' this perspective. The client needs to 'get caught up' in therapy and 'start working on it himself'. He needs to 'be ready to change his life and himself'. Vincent aims to help the client 'broaden his awareness': 'Draw attention to what the patient experiences, such as somatic symptoms (...). Broadening of awareness, increasing self-support, increasing competencies in the sense that he himself can decide more about his life.'

Therapist's position. Symptoms have specific causes that need to be addressed in psychotherapy. This causal way of thinking probably reflects Vincent's medical education and practice. There is a clear hierarchy in the psychotherapeutic relationship. Vincent takes responsibility for the client, especially at the beginning of therapy. From the position of a kind and respectful authority, Vincent legitimizes the client's troubling experiences: 'This was probably important for her. (...) That, unlike her, I did not see what was happening to her as something horrible. (...) She simply got scared. (...) She just needed some support and (...) she needed to hear that nothing truly horrible was happening, and that it would be all right again.'

Alternative strategy. Depending on the nature of the achieved change, Vincent distinguishes between 'relief' and 'recovery': 'He left with at least some small relief from his symptoms, but this is not a successful therapy for me. Success would be if he would recognize how he is creating the symptoms himself and what they tell him, and if he started to change his life accordingly.' When it is not possible to achieve the desired change in therapy, Vincent respects this as the actual limit of the client: 'He could sense that it would lead to some changes which (...) he would not like.' In such cases, Vincent turns to the medical approach: he educates the client and offers him medications and herbs. He calms the client and relies on the 'magic of the physician's reassurance': 'She was afraid she would not be able to walk normally again. I told her that was nonsense and that she will be alright. So, I used my role of a physician.'

\section{Magda: I cradle the client patiently}

Magda (Therapist 7) is a 54-year-old female clinical psychologist with 28 years of psychotherapy practice.

Case conceptualization. Magda understands the symptoms as an expression of "frozen emotional processes" that the client is unaware of. They are connected to situations in which actual emotions could not be experienced or expressed: 'Either great sorrow and loss or often some anger or hurt or trauma that could not be expressed. (...) So, it stays with the person and expresses itself through the body.' Through focusing consciously on experiencing a somatic symptom in relation to a certain demanding situation, therapy 'brings to life what was numbed'. Magda recognizes a sequence of processes leading to MUPS: The client who experienced anger with her husband turned it against herself, which then led to the development of MUPS. In therapy, Magda works in the opposite direction, starting from the end: By deepening the awareness associated with MUPS, the client re-experienced aggression, accepted the reality of her relationship with her husband, re-experienced sorrow, and in a safe therapeutic environment, she allowed herself to express her emotions. The MUPS often remain, but the client 'is dealing with them in a much more realistic way' in the broader context of her life conditions.

Therapeutic task. Magda focuses on creating a supportive therapeutic relationship. Experiencing the therapist's support leads to building the client's self-support, which, in turn, leads to change. The change comes with a modified approach to one's own body. Until now, the body was 'causing trouble'. Magda's task is to help the client find kindness in relation to her body, to experience it and understand it. The client 'would like her body to function, [she perceives her body] as an object, as a computer. (...) So, [she needs] to become kinder [to herself].' Magda challenges the client's somatic explanation of MUPS using an explorative and confrontative approach pointing to obvious contradictions between the client's explanation and observable behavior here and now in the therapy situation. Magda helps the client understand the dynamics of emotional processes related to MUPS in everyday situations.

Therapist's position. Magda takes the 'not-knowing approach', respecting that somatic symptoms are initially understandable neither for the client, nor for the therapist:

I did not understand that at all. (...) I hear how the clients understand it [the medical explanation]. (...) I need to wait a longer time until some information starts to make some kind sense to me, what it could be about. Simply, I need to be patient. 
Magda must not approach the client from an expert position. Such a non-expert approach, which differs from that experienced with medical doctors, provides the client with a corrective experience. Only then can the client be ready to accept the psychological explanation of MUPS. Magda patiently trusts the slow, self-healing process of therapy and respects 'the wisdom of resistances' and respects client's limited capacity, which stops the client from making excessively large changes: 'Whenever she would fully realize fully in a given moment that she would have to do something [very radical in her relationship with her husband], then a part of her inner dialogue would stop her [as if she would say to herself:] wait, maybe it [MUPS] is just a somatic issue anyway.'

Alternative strategy. When the change cannot be achieved through her basic strategy, Magda does not change her approach, she just intensifies her original strategy: 'it is simply necessary to be even more patient'. Magda needs to conceal her frustration from the client, especially at the beginning of the therapy. The therapist's task is to accept her own helplessness regarding MUPS and wait with respect and curiosity. Supporting the creation of a safe and trusting therapeutic relationship is crucial because even if the client is unable to make a visible change, the therapy works on the level of the "emotional field', the shared here-and-now. In this implicit way, Magda can support emotional change in the client through a corrective relational experience.

\section{Irena: I let the client learn from a strong woman}

Irena (Therapist 6) is a 42-year-old female psychologist with 18 years of psychotherapy practice.

Case conceptualization. According to Irena, the client needs to learn to physically sense her body. Then she can more sensitively monitor her bodily experiences in difficult life situations and consider her physical symptoms in a broader relational context, 'so that she becomes aware of the situation before the physical pain comes.' Irena attributes a symbolic meaning to MUPS: 'My first hypothesis certainly was that when the patient brought up pain in the pelvis (...), then it was some sexual or female issue.' Irena tries to convey this understanding to the client: 'Her skin started to hurt so that she would be protected against intimacy. (...) I told her that.'

Therapeutic task. Irena's task is to redirect the client back to her feelings, to 'go deep' to 'get to inner values'. The basic method is to build sensitivity to feelings that are experienced bodily: 'I repeatedly turned her back to her feelings, to experiencing her body, simply to monitor what was changing.' In addition, Irena believes that clients needlessly limit their understanding of their situation by focusing solely on their actual problems. Instead, Irena strives to 'broaden the context for understanding' and actively directs the client's attention to resources that are available to them in demanding situations: 'I constantly try to somehow remind her of her resources, inner or outer ones, which are at her disposal. So, I repeat this to her again and again.'

Therapist's position. Irena takes the position of an expert, who - from a professional distance - assesses both the difficulties and the resources of the client: 'With some clients (...), it is clear to me from the beginning who has the resources and who does not. Then I set my therapeutic goals accordingly.' Irena 'leads' the client to become aware of her emotions and demands that the client 'work hard between the sessions'. She advises the client in a kind way, from her position as a strong, yet authentic female authority: 'Sometimes I say: '(...) you need to exaggerate [emotional expression] a few times to learn how to deal with it.' At the same time, I say: 'your husband will definitely survive it." Irena leads the client from a power position: 'When it is needed, I pull her. I do not motivate her; I simply say directly what needs to be done'. However, her authority is a very humane one, she uses herself as a model for explaining how MUPS work: '[I told her:] 'Where I would scream, you experience it bodily'... And we made fun of that (...) [because] laughing strengthens the therapeutic alliance. (...) I sit there and laugh and say: 'I am so proud of you!'” Irena is clearly personally involved: 'I invested quite some effort in her and I still do. I love her, I care for her.'

Alternative strategy. When the above-mentioned strategy does not work, Irena resigns from pursuing change by searching for insights. She stops trying to produce changes directly and resorts to using techniques and consultancy: 'Mostly relaxation and imagination, these are a kind of rescue'. She directs the client: 'I do not motivate her, I rather tell her directly that she needs to keep visiting the rehabilitation practitioner regularly.' She also offers specific ideas for solving the client's problems, 'because she lacked the potential for discovering it herself.' Irena offers simple human support and an opportunity to share: 'The client does not have the resources for change, so I am a surrogate friend to her [...] so that she is not totally alone in it.' Irena lets herself 'be used (...) as a kind of anxiolytic'; she even perceives her position as 'a statefunded emotional prostitute'.

\section{Veronika: I teach the client to use emotions properly}

Veronika (Therapist 8 ) is a 41-year-old female psychologist with 17 years of psychotherapy practice.

Case conceptualization. Veronika understands symptoms as something caused by restraining emotions, especially aggression: 'The whole process of her symptoms was based on her holding back her aggression.' Veronika uses theoretical models to explain to the client how her symptoms are associated with emotions: '[I explained to her] how it is and why it is happening this way. (...): 'This is what is written [as a theory] and it actually seems to me that this principle also applies to your case." In psychotherapy, change occurs when the client learns 'to experience emotions and to be kind towards herself'. 
Therapeutic task. Veronika explains the psychological context and offers a coping strategy. 'I analysed the situation [with her husband] for her, I was helping her to see his motivations.' She relies on the theoretical frame that she learned in her psychotherapy training, and she tries to share it with the client: 'I helped her to understand how her disorder works in relation to her personality from a psychological standpoint. (...) And I offered her a strategy for how to get out of it.' Veronika demands personal involvement from the client. If the client does not accept the concept suggested to her, the therapist understands it as resistance and tries to eliminate it: 'I worked with the resistance for a long time, I tried to bring it into the therapy (...), but she always somehow went around it. So I ultimately ended [the therapy] and referred her to a colleague, who she refused, however.'

Therapist's position. Veronika perceives herself as the initiator of the change. She requires the client to actively take over the responsibility for change: 'I will not try to persuade someone who is objectively not willing, not trying, and not aiming anywhere.' Veronika uses her knowledge and skills to teach the client. At the same time, she offers kind patience: 'I trusted in my knowledge, theoretical background (...). And also in the patience and kindness I felt towards that woman.'

Alternative strategy. Veronika is very clear about her basic strategy, and when it does not work, she feels helpless. In such cases, she at least offers relaxation training. However, she continues to require the client's active personal involvement in what the therapist is offering to them. If this does not work, Veronika ends the therapy. 'We really worked on her resistance. (...) [But] she was not even willing to accept the fact that she does not want [to collaborate]. (...) So, as a logical consequence, we ended the therapy.' At the same time, however, Veronika is respectful to the client as a person, she acknowledges her limitations and does not accuse her of being unable to make a change. She also admits limitations on the side of the therapist and the therapy setting.

\section{General patterns}

In the final phase of our analysis, we adopted a more general perspective from which a crucial common pattern could be recognized: All the therapists were trying to convey their fundamental beliefs to their clients. Although the individual beliefs might have differed, we could see how the therapists were trying to pass on to their clients what they considered as healthy functioning. In the successful cases reported by the therapists, the clients seemed to have adopted these fundamental beliefs of their therapists and started to make changes in their lives accordingly.

At the same time, we could see that each of the therapists used their own unique approach to convey their beliefs. The difference was in the relational setting with the client, which varied on the scale between two extreme poles:

\section{EXPERT LEADERSHIP $\longleftrightarrow$ JOINT EXPLORATION}

On one side, there is an explicit position of a directive teacher who knows what is healthy and offers expert leadership: I want to teach the client what I have learned to be useful. On the other hand, there is the position of an exploring companion: Together, we search for a meaningful way of understanding, which will provide the client with guidelines. From this position, the teaching was an implicit dialogical process in which the therapists were 'seducing' their clients into adopt the therapists' beliefs about healthy functioning.

However, the therapists also reflected on unsuccessful cases in which the clients did not accept the therapists' beliefs on healthy functioning. This point is especially important regarding clients with MUPS who often refuse to accept the psychological aspects of their somatic problems. They also tend to come to psychotherapy with low, or sometimes even negative, expectations after a long series of unsuccessful treatments with different specialists on somatic disorders. For both of these reasons, psychotherapists often reach the limits of their approach when working with MUPS clients.

In such cases, the therapists were pushed to modify the relational setting with the client.

We found that the therapists' flexibility was very limited in this regard. While on the level of specific therapeutic interventions, the therapists seemed to show high flexibility, on a more general level, they adhered to their favourite collaboration setting. In several cases, they had one more alternative to which they could switch, but no more than that. Accordingly, we distinguished four types of collaboration setting modifications the therapists used in unsuccessful cases:

1. Expert leadership was modified to Joint exploration. For example, Irena (I let the client learn from a strong woman) changed the Therapist's position from that of expert assessment and advice to offering simple human support and an opportunity to share. The Case conceptualization changed from 'The client needs to understand her physical symptoms in a broader relational context', to 'It is important that she is not totally alone in it.' The Tasks changed accordingly from 'Turning the client toward her bodily experienced feelings' to 'Becoming a substitutional friend for the client'.

2. Joint exploration was modified to Expert leadership. For example, Vincent (I lead the client to change her life) changed the Therapist's position from 'broadening awareness' in a safe and trusting therapeutic relationship to educating the client and offering medicines and herbs. The Case conceptualization changed from 'Symptoms signalize that the client is not living healthily, he is omitting the existential dimension of life', to 'Enabling the client to experience at least some small relief from his symptoms'. The Tasks changed accordingly from 'Raising competencies to 
decide more about one's own life by broadening awareness' to 'Calming the client down by using the magic of the doctor's reassurance'.

3. Joint exploration was modified to even more intense Joint exploration. For example, Magda (I cradle the client patiently), who patiently trusts the slow selfhealing process in the supportive therapeutic relationship, intensifies this approach by being even more patient, forcing the therapist to process their own frustration. The Case conceptualization ('Symptoms are an expression of frozen emotional processes') and the Therapist's position (Providing the client with a corrective relational experience) remained the same, but the Tasks became less ambitious and demanding (Being even more patient and concealing frustration from the client).

4. Expert leadership was modified to even more intense Expert leadership. For example, Veronika (I teach the client to use emotions properly) who, as the initiator of the change, explained the psychological context and offered a coping strategy, stressed this expert Therapist's position even more and became a relaxation trainer for the client. Case conceptualization (Symptoms as being caused by restraining emotions) remained the same, but the Tasks (Motivating the client to learn a relaxation technique) became less ambitious and more specific.

The way the therapists structure the relational setting with the client, and how they change it in unsuccessful cases, illustrated the personal therapeutic approach not only on the level of working strategies, but also from a more complex point of view. It enabled us to summarize each therapist's working strategies into one coherent picture.

\section{Discussion}

The present study is the first to explore PTA in Gestalt psychotherapists who reflected on their clinical work with clients suffering from MUPS. The first question of this study was 'In what ways do Gestalt therapists differ from each other when working with MUPS clients?' The question assumed that Gestalt psychotherapists would differ substantially in their work, as their PTA would overshadow the fact that they all used the same theoretical model and worked with the same group of clients (Baldwin \& Imel, 2013; Řiháček \& Roubal, 2017).

The results of our study show this assumption plausible, as shown by the differences identified among psychotherapists. Our results complement the already existing models of therapist's individualized approaches (Fernández-Alvarez, Gómez, \& García, 2015; Řiháček \& Roubal, 2017) with a new way of capturing the individual difference between therapists by focusing on therapist's understanding of the client's difficulties; on a therapist's task deduced from the conceptualization; on a relational position from which the therapist approaches their clients; and on the alternative strategy used when the treatment did not progress in the desired direction. The psychotherapists' clinical work represents creative adaptations of the therapeutic style with a specific group of clients, showing an individualized approach that is complementary to the usage of predefined treatment manuals (Wampold \& Imel, 2015). The need for a flexible use of techniques that aims to find a helpful focus of treatment for clients has been mentioned in other recent studies of professionals who focus on the treatment of people with MUPS (Balabanovic \& Hayton, 2019; Cevelicek et al., 2020). These clients are considered difficult to treat (Heijmans et al., 2011; Luca, 2012), a position supported by observably mediocre therapeutic results (Kleinstäuber et al., 2011; van Dessel et al., 2014), leaving a high desire to explore different approaches to engage them in treatment. A flexible usage of personal therapeutic styles, similar to the one demonstrated in the present study, might improve psychotherapy outcomes and client engagement, specifically when client characteristics such as psychotherapy preferences, stage of change, reactance level, coping style, and attachment style are accounted for (Norcross \& Wampold, 2018). The overview of different personal therapeutic styles that the therapists in our study used in the treatment of clients with MUPS challenges the assumptions of treatment manuals adherence and of treatment specificity (Wampold \& Imel, 2015), and may serve as an inspiration for other practitioners. However, it is important to note that not just any personal therapeutic style can be presented as effective. A personal style must make use of effective mechanisms of change grounded in a clearly defined theoretical model to be effective.

Since psychotherapists in the studied sample had considerable experience in the treatment of people with MUPS, multiple mechanisms of change were present in their work. For instance, even though the psychotherapists used different positions from which they approached clients in the relational field that unfolded during sessions (Francesetti, 2019), both the psychotherapist who used the position of a health-care authority and the therapist who assumed a not-knowing and non-hierarchical position used their positions to legitimize clients' symptoms and enhance their self-compassion. Similarly, the effective change mechanism of increasing clients' emotional awareness and regulation (Pourová et al., 2020) was invoked by both the psychotherapist teaching clients emotional management and redirecting clients back to their feelings.

The second question of the present study was 'What are the common principles that, on a meta-level, govern the functioning of the therapist's personal approach?' PTA represents a system with its own inner logic of organization and principles of development according to the core

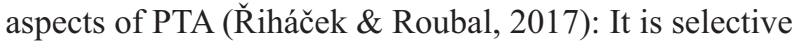
in an idiosyncratic way; created from metabolized theories and techniques; responsive to the context of a thera- 
peutic situation and evolves throughout a therapist's career. In our study, the role of the underlying beliefs was found crucial for each therapist's PTA. All the psychotherapists applied their views of healthy functioning and the changes they perceived as beneficial across clients and situations rather uniformly. Similarly, when eminent psychotherapists with different theoretical orientations were asked about their usage of beliefs in psychotherapy (Williams \& Levitt, 2007), they expressed that beliefs governed their emotional reactions to clients and, in turn, the psychotherapists used their emotional reactions to monitor client progress. However, the present study is the first to our knowledge that illustrates how therapists use their beliefs to determine the desired direction of change in clients with MUPS.

Since therapists' beliefs are intertwined with their perception of a desirable treatment outcome, it is not surprising that they associate clients' adoption of their beliefs with outcomes (Jadaszewski, 2017; Kelly, 1990). This is relevant in clients with MUPS who are perceived by professionals as often having views and characteristics that thwart what therapists consider to be healthy and useful in psychotherapy (Balabanovic \& Hayton, 2019; Heijmans et al., 2011; Luca, 2011). The effort to 'convert' clients' beliefs was even more apparent in this study because the psychotherapists perceived clients with MUPS as less open to change. Because suggestion is an effective factor in psychotherapy, 'converting' clients' beliefs about healthy functioning is considered a useful therapeutic strategy (Cuijpers, Reijnders, \& Huibers, 2019). Indeed, some psychotherapy approaches intentionally aim to change specific beliefs held by clients because they hypothesize dysfunctional beliefs to be the causal or maintaining factors in people suffering from MUPS (e.g., Salkovskis et al., 2016). The theoretical and empirical base of therapist's beliefs about healthy functioning supports their orientation in a complex situation. That said, the need for some flexibility in beliefs about healthy functioning might be an underrepresented theme in treatment and training.

\section{Study limitations}

Asking therapists about two of their recent psychotherapies with clients suffering from MUPS, one successful and one unsuccessful, could have influenced the variety of strategies we were able to capture. The therapists might use different positions, tasks, and conceptualizations with different clients. However, the aim of the present study was to capture the therapists' unique styles from an idiographic perspective, which was still possible within the chosen design. Although the chosen interview process could limit the range of captured strategies, it was successful in capturing the psychotherapists' beliefs connected to therapeutic success and healthy functioning in clients with MUPS.

We relied on the therapists' own descriptions of and reflections on their therapeutic work. These may not fully correspond to the therapists' actual behavior that would be reported by an external observer. While there is research showing that practitioners can accurately recall types of techniques they used (Castonguay et al., 2017), other studies suggest that the reliability of self-report is limited (Santa Ana et al., 2008).

The present study relied on a high degree of analytic inference from the researchers, i.e. it addressed themes that the respondents did not talk about explicitly. For instance, most of them did not explicitly formulate the positions they used in contact with clients. When a high degree of inference is used, data analysis may more often lead to alternative interpretations by different researchers. We attempted to reduce the risk of bias by including multiple researchers in the analysis process and by using the principles of consensuality (Hill, 2012). Admittedly, the results of the study are influenced by our focus on the uniqueness of each therapist's PTA. Researchers who would endeavour to find commonalities among the therapists in the first place would probably come to different conclusions.

The focus on Gestalt therapists might be perceived as reducing the generalizability of findings for practitioners of other therapeutic orientations. However, we believe that our results point to common factors (Pourová et al., 2020; Řiháček \& Čevelíček, 2019) rather than to the specifics of the Gestalt therapeutic approach in clinical practice (Francesetti, Gecele, \& Roubal, 2013) and work with psychosomatic clients specifically (Nemirinskiy, 2013). We hypothesize that similar variability could be found in other therapeutic orientations. However, this hypothesis must be tested in future studies.

\section{Conclusions and implication for training and practice}

The study revealed considerable diversity in the way psychotherapists work, even when they share the same approach and the same type of clients. The specific features of each personal therapeutic approach can be characterized by the particular therapist's Case conceptualization, Therapeutic task, and the Therapist's position. However, to understand a therapist's flexibility, this framework needs to be supplemented with explorations of the alternative strategies a therapist uses when working with an unsuccessful case.

Our finding that the therapists' unique style of working with clients suffering from MUPS resulted from their beliefs about general healthy functioning has implications for psychotherapy training. Psychotherapy trainees are usually taught specific theories of change that they should apply to clients, and they also tend to adopt their trainers' beliefs about healthy functioning. In the initial stage of development, trainees tend to apply these theories to clients (Maruniaková, Řiháček, \& Roubal, 2017; 
Maruniaková \& Řiháček, 2018), later discovering that many clients do not change as expected. Exploring the perspective of implicit theories of change, beliefs, and values, as they translate to interventions, therapeutic relationships, and psychotherapists' view of treatment success, could help broaden trainees' concepts of healthy functioning. The flexibility they thus develop might reduce their initial and unnecessary disappointments and protect clients from being pushed into 'boxes' into which they cannot fit.

\section{References}

Balabanovic, J., \& Hayton, P. (2019). Engaging patients with 'medically unexplained symptoms' in psychological therapy: An integrative and transdiagnostic approach. Psychology and Psychotherapy: Theory, Research and Practice, 1-20. doi:10.1111/papt.12213.

Baldwin, S. A., \& Imel, Z. E. (2013). Therapist effects: Findings and methods. In M. J. Lambert (Ed.), Bergin and Garfield's handbook of psychotherapy and behavior change (6th ed., pp. 258-297). Hoboken, NJ: John Wiley \& Sons.

Barber, P. (2006). Becoming a practitioner researcher, a Gestalt approach to holistic inquiry. London: Middlesex University Press.

Beutler, L. E., \& Bergan, J. (1991). Value change in counseling and psychotherapy: A search for scientific credibility. Journal of Counseling Psychology, 38(1), 16-24. doi:10.1037/00220167.38.1.16.

Brown, R. J. (2007). Introduction to the special issue on medically unexplained symptoms: Background and future directions. Clinical Psychology Review, 27(7), 769-780. doi:10.1016/ j.cpr.2007.07.003.

Brownell, P. (2008). Handbook for theory, research, and practice in Gestalt therapy. Newcastle: Cambridge Scholars Publishing.

Brownell, P. (2016). Contemporary gestalt therapy. In D. Cain, K. Keenan, \& S. Rubin (Eds.), Humanistic psychotherapies: Handbook of research and practice, Second Edition (pp. 219250). Washington, DC: American Psychological Association.

Cabaniss, D. L., Cherry, S., Douglas, C. J., \& Schwartz, A. R. (2011). Psychodynamic psychotherapy: A clinical manual. In Psychodynamic psychotherapy: A clinical manual. Hoboken, NJ: Wiley-Blackwell.

Caspi, A., Houts, R. M., Belsky, D. W., Goldman-Mellor, S. J., Harrington, H., Israel, S., ... \& Moffitt, T. E. (2014). The $p$ factor: One general psychopathology factor in the structure of psychiatric disorders? Clinical Psychological Science, 2(2), 119-137. doi:10.1177/2167702613497473.

Castonguay, L. G., Janis, R. A., Youn, S. J., Xiao, H., McAleavey, A., Boswell, J. F., ... \& O'Leary Wiley, M. (2017). Clinicians' prediction and recall of therapeutic interventions: Practice research network study. Counselling Psychology Quarterly, 30(3), 308-322. doi:10.1080/09515070.2017.1334628.

Čevelíček, M., Roubal, J., Hytych, R. \& Řiháček, T. (2019). What works in the treatment of medically unexplained physical symptoms? The psychotherapist perspective. Manuscript submitted for publication.

Charmaz, K. (2006). Constructing grounded theory: A practical guide through qualitative analysis. London: Sage Publications.
Cuijpers, P., Reijnders, M., \& Huibers, M. J. H. (2019). The role of common factors in psychotherapy outcomes. Annual Review of Clinical Psychology, 15(1), 207-231. doi:10.1146/annurev-clinpsy-050718-095424.

Elliott, R. (1998). Editor's introduction: A guide to the empirically supported treatments controversy. Psychotherapy Research, $8(2), 115-125$.

Fernández-Alvarez, H., Gómez, B., \& García, F. (2015). Bridging the gap between research and practice in a clinical and training network: Aigle's program. Psychotherapy Research, 25, 8494. doi:10.1080/10503307.2013.856047.

Francesetti G., Gecele M., \& Roubal J. (2013). Gestalt therapy approach to psychopathology. In Francesetti G., Gecele M., Roubal J. (Eds.), Gestalt therapy in clinical practice. From psychopathology to the aesthetics of contact (pp. 59-76). Milano: FrancoAngeli.

Francesetti, G., Gecele, M., \& Roubal, J. (2013). Gestalt therapy in clinical practice. From psychopathology to the aesthetics of contact. Milano: FrancoAngeli.

Francesetti, G. (2019). The field perspective in clinical practice. Towards a theory of therapeutic phronesis. In: Brownell P. (Ed.), Handbook for theory, research and practice in gestalt therapy (2nd ed.). Newcastle upon Tyne: Cambridge Scholars Publishing.

Francesetti, G., Alcaro, A., \& Settanni, M. (2020). Panic disorder: attack of fear or acute attack of solitude? Convergences between affective neuroscience and phenomenological-Gestalt perspective. Research in Psychotherapy: Psychopathology, Process and Outcome, 23, 77-87.

Glaser, G. G., \& Strauss, A. L. (1967). The discovery of grounded theory: Strategies for qualitative research. Chicago, IL: Aldine Publishing Company.

Heijmans, M., olde Hartman, T. C., van Weel-Baumgarten, E., Dowrick, C., Lucassen, P. L. B. J., \& van Weel, C. (2011). Experts' opinions on the management of medically unexplained symptoms in primary care. a qualitative analysis of narrative reviews and scientific editorials. Family Practice, 28(4), 444-455. doi:10.1093/fampra/cmr004.

Hopwood, C. J., Bagby, R. M., Gralnick, T., Ro, E., Ruggero, C., Kotov, R., ...\& Zimmermann, J. (2019). Integrating psychotherapy with the hierarchical taxonomy of psychopathology (HiTOP). Journal of Psychotherapy Integration. Advance online publication. doi:10.1037/int0000156.

Iaculo G. (2007). The psychosomatic disorders in a dependent personality. Gestalt Review, 11(1), 59-73.

Jacobs, L., \& Hycner, R. (Eds.) (2009). Relational approaches in gestalt therapy. New York: Gestalt Press.

Jadaszewski, S. (2017). Ethically problematic value change as an outcome of psychotherapeutic interventions. Ethics and Behavior, 27(4), 297-312. doi:10.1080/10508422.2016. 1195739.

Kelly, T. A. (1990). The role of values in psychotherapy: A critical review of process and outcome effects. Clinical Psychology Review, 10(2), 171-186. doi:10.1016/0272-7358 (90)90056-G.

Kelly, T. A., \& Strupp, H. H. (1992). Patient and therapist values in psychotherapy: Percieved changes, assimilation, similarity, and outcomes. Journal of Consulting and Clinical Psychology, 60(1), 34-40. doi: 10.1037/0022-006X.60.1.34

Kepner J.I. (1993), Body process. Working with the body in psychotherapy. Jossey-Bass Publishers, San Francisco CA.

Kleinstäuber, M., Witthöft, M., \& Hiller, W. (2011). Efficacy of short-term psychotherapy for multiple medically unexplained 
physical symptoms: a meta-analysis. Clinical Psychology Review, 31(1), 146-160.

Lini, C., \& Bertrando, P. (2019). Finding one's place: emotions and positioning in systemic-dialogical therapy. Journal of Family Therapy, 1-2. doi:10.1111/1467-6427.12267.

Luca, M. (2011). A qualitative study of psychodynamic and cognitive behavioural therapists' conceptualisations of medically unexplained symptoms in their clients. Counselling \& Psychotherapy Research, 11(4), 291-299. doi:10.1080/14733145. 2010.528007.

Luca, M. (2012). Therapeutic activities and psychological interventions by cognitive behavioural and psychodynamic therapists working with medically unexplained symptoms: a qualitative study. Counselling and Psychotherapy Research, 12(2), 118-127. doi:10.1080/14733145.2011.605455.

Maruniaková, L., \& Řiháček, T. (2018). How beginning cognitive behavioural therapists develop professional confidence. The Cognitive Behaviour Therapist, 11(e5), 1-19.

Maruniaková, L., Řiháček, T., \& Roubal, J. (2017). How beginning counselors learn: The interaction of personal and professional experiences in counselors with an experiential orientation. Counselling Psychology Quarterly, 30(1), 48-66.

Nemirinskiy, O. (2013). Gestalt approach to psychosomatic disorders. In Francesetti, G., Gecele, M., Roubal, J. (Eds.), Gestalt therapy in clinical practice. from psychopathology to the aesthetics of contact (pp. 573-587). Milano: FrancoAngeli.

Norcross, J. C., \& Wampold, B. E. (2018). A new therapy for each patient: Evidence - based relationships and responsiveness. Journal of Clinical Psychology, 74(11), 1-18. doi:10.1002/ jclp.22678.

Orlinsky, D. E., \& Rønnestad, M. H. (Eds.) (2005). How therapists develop: a study of therapeutic work and professional growth. Washington, DC: American Psychological Association.

Perls, F. Hefferline, R., \& Goodman, P. (1951). Gestalt therapy. Excitement and growth in the human personality. Highland, NY: Gestalt Journal Press.

Philippson, P. (2009). The emergent self. An existential-gestalt approach. London: Karnac Books.

Pourová, M., Klocek, A., ̌̌iháček, T., \& Čevelíček, M. (2020). Therapeutic change mechanisms in adults with medically unexplained physical symptoms: a systematic review. Journal of Psychosomatic Research, 134.

Řiháček, T., \& Čevelíček, M. (2019). Common therapeutic strategies in psychological treatments for medically unexplained somatic symptoms. Psychotherapy Research. Advanced online publication. doi:10.1080/10503307.2019.1645370.

Řiháček, T., \& Roubal, J. (2017). Personal therapeutic approach: concept and implications. Journal of Psychotherapy Integration, 27(4), 548-560. doi:10.1037/int0000082.

Roubal, J., Francesetti, G., Brownell, P., Melnick, J., ZeleskovDjoric, J. (2016). Bridging practice and research in gestalt therapy. In Roubal, J. (Ed.), Towards a research tradition in Gestalt therapy (pp. 1-17). Newcastle upon Tyne: Cambridge Scholars Publishing.

Roubal J., Francesetti G., \& Gecele M. (2017). Aesthetic diagnosis in Gestalt therapy. Behavioral Sciences, Basel, Switzerland: MDPI AG, 7(4). doi:10.3390/bs7040070.

Salkovskis, P. M., Gregory, J. D., Sedgwick-Taylor, A., White, J., Opher, S., \& Ólafsdóttir, S. (2016). Extending cognitive-behavioural theory and therapy to medically unexplained symptoms and long-term physical conditions: a hybrid transdiagnostic/problem specific approach. Behaviour Change, 33(4), 172-192. doi:10.1017/bec.2016.8.

Santa Ana, E. J., Martino, S., Ball, S. A., Nich, C., Frankforter, T. L., \& Carroll, K. M. (2008). What is usual about 'treatmentas-usual'? Data from two multisite effectiveness trials. Journal of Substance Abuse Treatment, 35(4), 369-379. doi:10.1016/j.jsat.2008.01.003.

Sichera, A. (2001). A confronto con Gadamer: Per una epistemologia ermeneutica della Gestalt. In Spagnuolo Lobb, M. (Ed.), Psicoterapia della Gestalt. Ermeneutica e clínica (pp. 17-41). Milano: FrancoAngeli.

Strümpfel, U., \& Goldman, R. (2001). Contacting gestalt therapy. In D. Cain \& J. Seeman (Eds.), Humanistic psychotherapies: handbook on research and practice (pp. 189-219). Washington, American Psychological Associationß.

Strümpfel, U. (2006). Therapie der Gefühle. Forschungsbefunde zur Gestaltherapie. Bergisch Gladbach; EHP.

van Dessel, N., den Boeft, M., van der Wouden, J. C., Kleinstäuber, M., Leone, S., Terluin, B., Numans, M., ... \& van Marwijk, H. (2014). Non-pharmacological interventions for somatoform disorders and medically-unexplained physical symptoms (MUPS) in adults (Protocol). Cochrane Database Syst Rev, 11(6), CD011142.

Wampold, B. E. (2015). How important are the common factors in psychotherapy? An update. World Psychiatry, 14(3), 270277. doi:10.1002/wps.20238.

Wampold, B. E., \& Imel, Z. E. (2015). The great psychotherapy debate: The evidence for what makes psychotherapy work (2nd ed.). New York, NY: Routledge.

Williams, D. C., \& Levitt, H. M. (2007). A qualitative investigation of eminent therapists' values within psychotherapy: Developing integrative principles for moment-to-moment psychotherapy practice. Journal of Psychotherapy Integration, 17(2), 159-184. doi:10.1037/1053-0479.17.2.159. 